\title{
BMJ Open Term perinatal mortality audit in the Netherlands 2010-2012: a population-based cohort study
}

\author{
Martine Eskes, ${ }^{1,2}$ Adja J M Waelput, ${ }^{1}$ Jan Jaap H M Erwich, ${ }^{3}$ Hens A A Brouwers, ${ }^{4}$ \\ Anita C J Ravelli, ${ }^{2}$ Peter W Achterberg, ${ }^{5}$ Hans (J) M W M Merkus, ${ }^{1}$ \\ Hein W Bruinse ${ }^{1}$
}

To cite: Eskes M, Waelput AJM, Erwich JJHM, et al. Term perinatal mortality audit in the Netherlands 2010-2012: a populationbased cohort study. BMJ Open 2014;4:e005652. doi:10.1136/bmjopen-2014005652

- Prepublication history for this paper is available online. To view these files please visit the journal online (http://dx.doi.org/10.1136/ bmjopen-2014-005652).

Received 8 May 2014 Revised 19 September 2014 Accepted 23 September 2014

CrossMark

For numbered affiliations see end of article.

Correspondence to

Martine Eskes;

martine.eskes@hetnet.nl

\section{ABSTRACT}

Objective: To assess the implementation and first results of a term perinatal internal audit by a standardised method.

Design: Population-based cohort study.

Setting: All 90 Dutch hospitals with obstetric/ paediatric departments linked to community practices of midwives, general practitioners in their attachment areas, organised in perinatal cooperation groups (PCG).

Population: The population consisted of 943 registered term perinatal deaths occurring in 2010-2012 with detailed information, including 707 cases with completed audit results.

Main outcome measures: Participation in the audit, perinatal death classification, identification of substandard factors (SSF), SSF in relation to death, conclusive recommendations for quality improvement in perinatal care and antepartum risk selection at the start of labour.

Results: After the introduction of the perinatal audit in 2010, all PCGs participated. They organised 645 audit sessions, with an average of 31 healthcare professionals per session. Of all 1102 term perinatal deaths $(2.3 / 1000)$ data were registered for $86 \%(943)$ and standardised anonymised audit results for $64 \%$ (707). In $53 \%$ of the cases at least one SSF was identified. Non-compliance to guidelines $(35 \%)$ and deviation from usual professional care $(41 \%)$ were the most frequent SSF. There was a (very) probable relation between the SSF and perinatal death for $8 \%$ of all cases. This declined over the years: from $10 \%$ $(n=23)$ in 2010 to $5 \%(n=10)$ in $2012(p=0.060)$. Simultaneously term perinatal mortality decreased from 2.3 to $2.0 / 1000$ births $(p<0.00001)$. Possibilities for improvement were identified in the organisation of care (35\%), guidelines or usual care $(19 \%)$ and in documentation (15\%). More pregnancies were antepartum selected as high risk, $70 \%$ in 2010 and $84 \%$ in 2012 ( $p=0.0001)$.

Conclusions: The perinatal audit is implemented nationwide in all obstetrical units in the Netherlands in a short time period. It is possible that the audit contributed to the decrease in term perinatal mortality.

\section{Strengths and limitations of this study}

- The Netherlands is the first country in which all collaborating perinatal healthcare professionals nationwide participate in an internal perinatal audit systematically performed at the local level.

- Within 2 years all hospitals in the country providing obstetric/paediatric care with their surrounding midwifery practices participated in the perinatal audit.

- The perinatal audit resulted in description of substandard factors (SSF), relation to death and the formulation of many recommendations mostly ready for implementation.

- Not all term perinatal deaths are audited. Characteristics of the audited cases are comparable to all term perinatal deaths in the national registration.

- Of all audited cases information was insufficient in $11 \%$ for SSF assessment. This is a major point of attention for the years ahead.

\section{INTRODUCTION}

Perinatal mortality is an important indicator of the quality of perinatal care. ${ }^{1}$ In 2000 the Netherlands had the highest perinatal mortality rate when compared with a large group of European countries. ${ }^{2} 3$ Although perinatal mortality in the Netherlands has decreased in recent years, in 2010 the ranking relative to other European countries showed only a modest improvement. ${ }^{45}$

These outcomes of the international benchmarks were an important incentive for Dutch politicians and professionals in the field of perinatal care to investigate the determinants of perinatal mortality including assessment of the quality of care. One of the possible interventions in this regard was the introduction of the perinatal audit, a critical and systematic analysis of the quality of perinatal care. ${ }^{6}$ Earlier, the introduction of a perinatal audit in Norway was an important 
factor in improving the quality of perinatal care and preceded a decline of perinatal mortality in Norway. ${ }^{7-9}$

In the Netherlands, perinatal audit studies were undertaken in the eighties of the past century. These audits were local or regional one-time studies. ${ }^{10-12}$ Recently, the professional organisations involved jointly prepared a nationwide perinatal mortality audit programme that would become a standard part of perinatal care. ${ }^{13-17}$ The Foundation Perinatal Audit in the Netherlands (PAN) was set up by the professional organisations of midwives, general practitioners, obstetricians, paediatricians and pathologists (http://www. perinataleaudit.nl). The first nationwide Dutch perinatal mortality audit started in the period 2010-2012 with a focus on audit of term perinatal deaths.

PAN receives annual funding from the Ministry of Health of about $€ 900000$. A third of the budget is used for support of perinatal cooperation groups (PCG) by regional teams. About $30 \%$ is intended for use and management of the registration systems and for reporting and communication (both including personnel costs). Another third is needed for the PAN office, board and advisory committees.

The objective of this study is to describe the implementation process of this perinatal audit programme and to present the results after the first 3 years of the term perinatal audit: perinatal death classification, antepartum high-risk selection, identification of substandard (care) factors (SSF), SSF in relation to death and conclusive recommendations for quality improvement in perinatal care.

\section{METHODS}

\section{Organisation and training}

A regional infrastructure with audit support teams has been set up. The teams consist of healthcare professionals in the 10 tertiary centres for perinatology with a neonatal intensive care unit (NICU) and obstetric 'high care' department facilities. These regional teams were trained by PAN for coordination and support of the audit performance at local (hospital) levels. Subsequently these regional teams trained the audit teams of the local hospitals and the surrounding practices of independent community midwives and general practitioners within their region. PAN cooperated with the IMPACT project that pioneered the introduction of perinatal audit in the Northern region of the Netherlands. ${ }^{18}$ PAN offered regular training sessions in organisation of the audit, in making narratives, in chairing of the audit meeting and in classification of perinatal mortality.

In January 2010, the nationwide Dutch perinatal mortality audit officially started with the audit of term perinatal deaths as the first topic. This topic was chosen because of the involvement of all professional groups in the obstetric/paediatric/neonatal field in term pregnancies and deliveries. Within the Netherlands community midwives and, on a small scale, general practitioners provide obstetric care (including home births) to women with antepartum-judged low-risk profiles. If complications (threaten to) occur the responsibility for obstetric care is transferred to a medical specialist in a general hospital (secondary care) or tertiary centre. Risk selection during pregnancy and labour in primary or secondary or tertiary care is therefore the essence of Dutch perinatal care organisation. ${ }^{19-21}$

The Netherlands is divided into 10 perinatal healthcare regions, catchment areas for perinatal high care centres that have NICU facilities. In 2012 there were 90 hospitals with obstetric/paediatric care facilities (97 in 2010 and 93 in 2011). Each hospital and the surrounding community practices of independent midwives and general practitioners are organised in a PCG. Each PCG is responsible for auditing and registration of the mortality cases in their catchment area.

Representatives of the professionals of the PCG analyse the cases in a systematic way, identify SSF in delivered care and/or organisation of care, identify the types of professionals involved and classify mortality according to three different systems, that is, the Wigglesworth/Hey, Modified ReCoDe and Tulip classifications. ${ }^{22-26}$ During the audit, the professionals relate the degree (none/unlikely, possible, (very) probable, unknown) to which SSF was the cause of death. Specific recommendations for improving the quality of care are then formulated. An independent chairperson presides over the audit and provides a safe environment. The individual is a perinatal healthcare professional not practising in the hospital/PCG where the audit takes place and is often a member of the regional audit team.

An audit with (involved) professionals is a delicate matter and needs to follow careful procedure. The PAN has developed basic rules to enable a safe environment.

- Everything discussed during the audit is confidential. Every participant signs for this.

- Each participant is an expert in her or his own professional field, participants can question professionals in other fields but do not judge them.

- The provided care and cure are assessed by comparison to formal guidelines or usual care, not by personal judgement.

- Narratives of the discussed cases that were drawn up before the meeting by members of the PCG are destroyed after the audit.

\section{Definitions}

Term perinatal mortality is defined as stillbirth and neonatal mortality during the first 4 weeks of life in births with gestational age from 37 weeks onwards, including the post-term period. ${ }^{27}$ Cases with unknown gestational age are excluded.

A SSF is present if care deviated from the safe limits of practice as laid down in national guidelines, local protocols (translation of national guidelines for local use) or normal professional practice. ${ }^{28}$ The formal agreed guidelines are accessible at the websites of the 
professional organisations of the midwives (25 topics), obstetricians (63), paediatricians (29) and general practitioners (3). The agreed referral list for primary and secondary care (VIL, Obstetric Indication List) comprises 125 items ${ }^{14}$ (translated in English). ${ }^{21}$ Most guidelines and the referral list items are covering term pregnancies as well. All agreed national guidelines in perinatology and the Obstetric Indication list are also available on the PAN website, arranged by professional organisation and by topic (http://www.perinataleaudit. $\mathrm{nl} /$ bibliotheek/richtlijnen/aandoeningen).

Antepartum low-risk assessment is defined as antepartum-judged low-risk profile for care during labour and delivery by primary care professionals (community midwife or general practitioner), including delivery at home. ${ }^{19-21}$

\section{Registries}

Because the audit focuses on recent cases that require more detailed and up-to-date information than is present in the national Dutch perinatal registry (PRN, Perinatal Registry of The Netherlands), two specific realtime databases were created to support the audit. The first is for the registration of perinatal death cases to be audited (PRN-Audit, Perinatal Audit Registry of The Netherlands) and the second for the confidential registration of the audit process and its outcomes (PARS, Perinatal Audit Registry System).

\section{PRN-Audit database}

Term perinatal mortality deaths are registered in PRN-Audit by healthcare professionals. Data are gathered from the medical records and registered with specific details needed to construct the narrative that will be used during the audit. In PRN-Audit supplemental information is included such as professionals involved in the care process, diagnostics, policy decisions, actions (treatments, referrals) and antepartum risk selection with their time frames. The audit narrative, the basic document for the audit meeting, is automatically generated from the PRN-Audit database as an anonymous document.

\section{PARS database}

The audit meetings (participants, number of cases discussed) and the outcomes of the audits are registered by the local audit groups in a separate database PARS. Because of privacy restrictions and to create a safe and secure environment for audit participants the PARS database is anonymous; only characteristics such as gestational age (categories) at birth, time (fetal-neonatal) of death and the perinatal death classifications are registered in PARS.

\section{PRN registry as reference}

The standard national PRN registry contains populationbased information on all pregnancies, deliveries from 22 weeks onwards and (re)admissions occurring until
28 days after delivery. The data are collected by different professionals and are linked when year data sets are available which is 1.5 years afterwards. The PRN data is made available to healthcare providers, researchers and policymakers. The completeness of PRN is currently around $96-98 \%$ of all births (http://www.perinatreg.nl). The national PRN database is the reference source for the audit cases in our study.

\section{Statistical methods}

Frequencies and descriptive statistics were expressed as $\mathrm{n}$ (\%). For testing group differences, we used $\chi^{2}$ for categorical variables.

\section{RESULTS}

A total of $943 / 1102(86 \%)$ of term perinatal deaths in the period 2010-2012 are registered in the PRN-Audit database and $707(64 \%)$ cases were audited and recorded in the PARS database. Compared with the number of cases in the national perinatal registry PRN, the number of cases that were registered in the PRN-Audit database increased over the years (from $85 \%$ in 2010 to $89 \%$ in 2012, $\mathrm{p}=0.04$ ) and the registration of cases in PARS showed an increase of 59\% in 2010 to $66 \%$ in 2012, $\mathrm{p}=0.015$ (table 1 ).

\section{Number of audit meetings and participants}

Throughout the Netherlands, 645 audit meetings took place in 2010-2012 with a total of 20091 participating healthcare professionals as community (independent) midwives, general practitioners, obstetricians, clinical midwives, nurses, paediatricians, pathologists, registrars, medical students and students in midwifery (with an average of 31 healthcare professionals per session). The number of participants nearly doubled in 2012 as compared with 2010. Half of the participants were once present, $15 \%$ twice and $35 \%$ three or more times. Audit participation of all the PCGs reached full coverage in the second year (2011; table 1).

\section{Substandard factors}

In 53\% (376) of the 707 audited cases one or more SSFs were identified (table 2).

A total of 717 SSFs emerged. In $35 \%$ of the cases these were related to non-compliance with guidelines or missing appropriate local protocols and in $41 \%$ they implied deviation from usual professional care (table 3).

Examples of deviations from guidelines are: no or delayed consultation of the obstetrician in case of suspected fetal growth restriction, no fetal monitoring in case of induction of labour, expectant management in case of non-reassuring cardiotocography and nonoptimal application of the guideline for resuscitation of the new born. Examples of deviation from usual professional care are: no fetal monitoring in case of vaginal blood loss, no consultation or action undertaken in case of decreased fetal movements, no further diagnosis 
Table 1 Term perinatal deaths and audit implementation parameters 2010-2012

\begin{tabular}{|c|c|c|c|c|c|c|c|c|c|}
\hline & \multicolumn{2}{|l|}{2010} & \multicolumn{2}{|l|}{2011} & \multicolumn{2}{|l|}{2012} & \multicolumn{2}{|c|}{ 2010-2012 } & \multirow[b]{2}{*}{ p Value* } \\
\hline & $\mathbf{n}$ & Per cent & $\bar{n}$ & Per cent & $\bar{n}$ & Per cent & $\mathbf{n}$ & Per cent & \\
\hline Term born children (PRN) & 163276 & & 163248 & & 160714 & & 487238 & & \\
\hline \multicolumn{10}{|c|}{ Term death cases and rate (PRN) } \\
\hline Perinatal & 379 & 0.23 & 398 & 0.24 & 325 & 0.20 & 1102 & 0.23 & $<0.00001$ \\
\hline Fetal & 249 & 0.15 & 252 & 0.15 & 217 & 0.14 & 718 & 0.15 & $<0.00001$ \\
\hline Neonatal & 130 & 0.08 & 146 & 0.09 & 108 & 0.07 & 384 & 0.08 & $<0.00001$ \\
\hline $\begin{array}{l}\text { Term death cases in } \\
\text { PRN-Audit }\end{array}$ & 324 & 85 & 329 & 83 & 290 & 89 & 943 & 86 & 0.04 \\
\hline Term death cases in PARS & 222 & 59 & 272 & 68 & 213 & 66 & 707 & 64 & 0.015 \\
\hline Number PCG & 97 & & 93 & & 90 & & - & & \\
\hline Audit participation of PCG & 94 & 97 & 93 & 100 & 90 & 100 & - & & \\
\hline Meetings & 149 & & 244 & & 252 & & 645 & & \\
\hline Participants & 4,291 & & 7,557 & & 8,243 & & 20091 & & \\
\hline
\end{tabular}

and/or action in case of presumed growth restriction and insufficient documentation in the medical records (medication, diagnostic considerations and policy).

\section{Cause of death}

Autopsy was performed in $38 \%$ and pathological examination of the placenta in $77 \%$ of the term cases registered for audit. Table 4 gives the results of the death classifications.

In the Tulip classification, in $36 \%$ of cases the underlying cause of death is classified as 'placental' and subclassified as placental pathology (development, parenchyma, localisation, 31\%), followed by umbilical cord complications (28\%) and placental bed pathology (28\%). Congenital malformation was classified in $19 \%$ as the underlying cause of death. In $32 \%$ of cases the cause of death is unknown. Using the ReCoDe classifications placental pathology was the most important clinical condition (24\%) with placental insufficiency $(n=108)$ and placental abruption for 26 cases as main groups. The Wigglesworth/Hey classification shows $62 \%$ fetal

Table 2 Number of substandard factors (SSF) assessed per case of term perinatal death 2010-2012

\begin{tabular}{llc}
\hline SSF per case & $\mathbf{n}$ & Per cent \\
\hline No SSF & 252 & 36 \\
$\geq 1$ SSF & 376 & 53 \\
1 & 213 & 30 \\
2 & 73 & 10 \\
3 & 43 & 6 \\
4 & 27 & 4 \\
$\geq 5$ & 20 & 3 \\
Insufficient information & 79 & 11 \\
Total cases & 707 & 100 \\
\hline
\end{tabular}

death and $15 \%$ of the pregnancies had a gestational age of $\geq 41$ weeks (table 4 ).

SSF, relation to death and professional involvement

In $8 \%$ (57) of the 707 audited cases the relation of SSF to death was assessed as probable or very probable and in $13 \%$ (92) as possible. The percentage of cases with one or more SSF remained stable during the years. Of these the cases with none/unlikely relation of SSFs to death increased from $20 \%$ in 2010 to $30 \%$ in 2012 $(\mathrm{p}=0.028)$. The rate of cases with SSF possibly related to death remained the same during the years, the cases with SSF (very) probably related to death decreased from $10 \%$ to $5 \%$ ( $\mathrm{p}=0.060$; table 5$)$.

In total, 1269 healthcare professionals played a role in SSFs in 376 cases: mean 3.4 professionals per case. Of them, $26 \%$ were obstetricians, $20 \%$ independent community midwives and $12 \%$ clinical midwives. Nurses were involved in $10 \%$ of the cases, paediatricians in $7 \%$ and registrars in $10 \%$ of the cases.

\section{Antepartum low risk assessment}

For $19 \%$ (183) of all registered cases there was antepartum low-risk selection for primary care delivery. Antepartum high-risk assessment showed a significant increase from $70 \%$ to $84 \%(p=0.0001$; table 6$)$.

Table 3 Categories of all 717 substandard factors (SSF) in 376 term perinatal deaths of infants born in 2010-2012

\begin{tabular}{llc}
\hline Category SSF & n & Per cent \\
\hline Non-compliance of guidelines or local & 250 & 35 \\
protocols missing & & \\
Deviation from usual professional care & 294 & 41 \\
Other & 173 & 24 \\
Total SSF & $717^{\star}$ & 100 \\
\hline *Per case more SSFs can be present. & &
\end{tabular}


Table 4 Tulip classification, modified ReCoDe classification and Wigglesworth/Hey classification of term perinatal deaths (2010-2012)

Tulip classification of perinatal mortality (underlying cause of death, main groups and placental subgroups) ${ }^{25}$

\begin{tabular}{|c|c|c|c|c|c|c|}
\hline & $\mathbf{n}$ & Per cent & & & $\mathbf{n}$ & Per cent \\
\hline Congenital anomaly & 135 & 19 & & & & \\
\hline Placenta & 253 & 36 & $\rightarrow$ & Placenta & & \\
\hline Infection & 32 & 5 & & Umbilical cord & 70 & 28 \\
\hline Other & 52 & 7 & & Placental bed & 71 & 28 \\
\hline Unknown & 224 & 32 & & Development & 42 & 17 \\
\hline No information & 11 & 2 & & Parenchyma & 31 & 12 \\
\hline \multirow{3}{*}{ Total } & 707 & 100 & & Localisation & 6 & 2 \\
\hline & & & & NOS & 33 & 13 \\
\hline & & & & Total & 253 & 100 \\
\hline \multicolumn{7}{|c|}{ Modified ReCoDe classification, most relevant condition at death (main groups and placental subgroups) 2324} \\
\hline & $\mathbf{n}$ & Per cent & & & $\mathbf{n}$ & Per cent \\
\hline Fetus group & 85 & 13 & & & & \\
\hline Neonate & 129 & 20 & & & & \\
\hline Umbilical cord & 60 & 9 & & & & \\
\hline Placenta & 155 & 24 & $\rightarrow$ & Placenta & & \\
\hline Amniotic fluid & 4 & 1 & & $\begin{array}{l}\text { Placental } \\
\text { abruption }\end{array}$ & 26 & 17 \\
\hline Uterus & 6 & 1 & & Placenta praevia & 2 & 1 \\
\hline Mother & 26 & 4 & & Vasa praevia & 9 & 6 \\
\hline Intrapartum & 28 & 4 & & $\begin{array}{l}\text { Placental } \\
\text { insufficiency }\end{array}$ & 108 & 70 \\
\hline Trauma & 2 & 0 & & Other & 10 & 6 \\
\hline Unclassified & 130 & 20 & & Total & 155 & 100 \\
\hline Unknown & 31 & 5 & & & & \\
\hline Total & 656 & 100 & & & & \\
\hline Not eligible & $51^{*}$ & & & & & \\
\hline \multicolumn{7}{|c|}{ Wigglesworth/Hey classification ${ }^{22}$} \\
\hline \multirow[b]{2}{*}{ Delivery at } & \multicolumn{2}{|l|}{ Fetal } & \multicolumn{2}{|l|}{ Neonatal } & Unknown period & \multirow{2}{*}{$\begin{array}{l}\text { Total } \\
\mathbf{n}\end{array}$} \\
\hline & $\mathrm{n}$ & Per cent & $\mathrm{n}$ & Per cent & $\begin{array}{ll}n & \text { Per cent }\end{array}$ & \\
\hline 37-40.6 weeks & 373 & 62 & 217 & 36 & 1 & 598 \\
\hline$\geq 41$ weeks & 67 & 61 & 42 & 39 & - & 109 \\
\hline Total & 440 & 62 & 259 & 37 & 8 & 707 \\
\hline
\end{tabular}

${ }^{*}$ During the first year missing data because of registration limitation for ReCoDe most relevant condition.

NOS, not otherwise specified. 
Table 5 Substandard factors (SSF) and relation to death in term perinatal deaths in 2010-2012

\begin{tabular}{|c|c|c|c|c|c|c|c|c|c|}
\hline \multirow[b]{2}{*}{ Relation to death } & \multicolumn{2}{|c|}{2010} & \multicolumn{2}{|c|}{2011} & \multicolumn{2}{|c|}{2012} & \multicolumn{2}{|c|}{ 2010-2012 } & \multirow[b]{2}{*}{ p Value* } \\
\hline & $\bar{n}$ & Per cent & $\bar{n}$ & Per cent & $\bar{n}$ & Per cent & $\bar{n}$ & Per cent & \\
\hline Cases with SSF & 116 & 52 & 147 & 54 & 113 & 53 & 376 & 53 & 0.92 \\
\hline None/unlikely & 45 & 20 & 75 & 28 & 63 & 30 & 183 & 26 & 0.028 \\
\hline Possible & 28 & 13 & 32 & 12 & 32 & 15 & 92 & 13 & 0.47 \\
\hline (very) probable & 23 & 10 & 24 & 9 & 10 & 5 & 57 & 8 & 0.060 \\
\hline Unknown & 20 & 9 & 16 & 6 & 8 & 4 & 44 & 6 & 0.053 \\
\hline Cases without SSF & 75 & 34 & 97 & 36 & 80 & 38 & 252 & 36 & 0.71 \\
\hline Cases with insufficient information & 31 & 14 & 28 & 10 & 20 & 9 & 79 & 11 & 0.26 \\
\hline Total cases & 222 & 100 & 272 & 100 & 213 & 100 & 707 & 100 & \\
\hline
\end{tabular}

al cases

Bold typeface indicates significance.

Table 6 Level of care at start of labour, period of death and year of birth in term perinatal

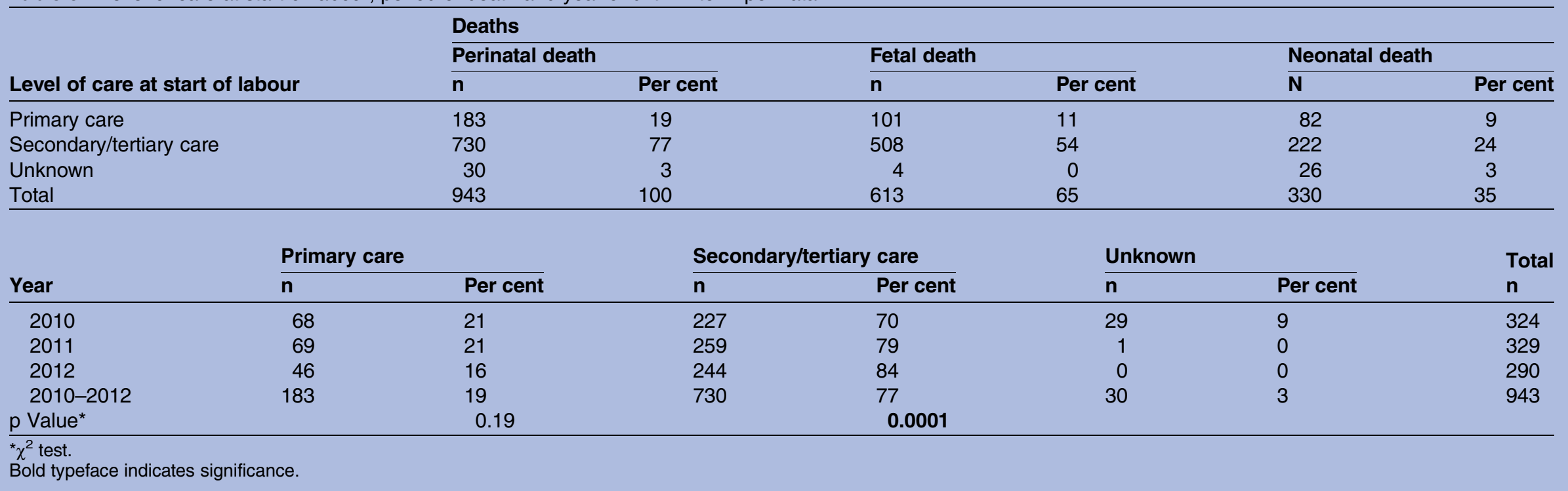


Recommendations from the audit

A total of 512 SSFs were identified in the 376 cases with one or more SSFs: in $57 \%$ (213) of the cases one SSF, in $19 \%$ (73) two SSFs and in 24\% (90) three or more SSFs. This leads to 603 recommendations: in $71 \%$ of all indicated SSFs $(512 / 717)$ one recommendation is described, and in $6 \%$ (41) two and sometimes three recommendations.

Recommendations were, in $35 \%$, about the organisation of care as well as for the quality of cooperation inside and outside the hospital between the different professional groups. In $19 \%$ the recommendations were for better use of guidelines and following usual care. The recommendations for guidelines focused on the development or adjustment of local protocols. In addition recommendations are given for producing local protocols for usual care. A specific frequently pronounced recommendation was the development of a national guideline for reduced fetal movements. In $15 \%$ the recommendations are to do with better documentation of the care process. The advice for better communication $(11 \%)$ refers to improvement of communication between professionals in community and hospital care. For training and education $(17 \%)$ recommendations were formulated, for instance training in neonatal resuscitation and in cardiotocography interpretation courses. ${ }^{26}$

On the PAN website all recommendations are sorted in groups and extensively elaborated http://www. perinataleaudit.nl/onderwerpen/204/uitwerking-vanaanbevelingen.

\section{Representativeness of the documented and audited cases}

Distribution of gestational age, congenital malformation and fetal-neonatal death are comparable in PARS and PRN registry (table 7).

The characteristics of the cases from 2010 to 2012 in the PRN-Audit database and in the national PRN database are comparable with regard to maternal characteristics such as parity, maternal age and gestational age except for a lower percentage of women of non-Caucasian ethnicity $(\mathrm{p}=0.04)$ and for less infants with birth weight $<2000 \mathrm{~g}$ ( $\mathrm{p}=0.01$; table 7$)$.

\section{DISCUSSION}

The Netherlands is the first country with a nationwide perinatal audit that is now systematically performed by all collaborating perinatal healthcare professionals at the local level. Within 2 years of its inception, all hospitals that provide perinatal care with the surrounding and adherent midwifery practices in the country participated in the perinatal audit. It proved feasible to audit and register the results of $64 \%$ (707) of all term perinatal deaths, which was a well representative sample of all term perinatal deaths in the Netherlands. The perinatal audit resulted in the description of SSFs and many recommendations ready for implementation within the PCG.

During the 3-year audit period term perinatal mortality decreased from 2.3 to $2 / 1000$ births $(p=<0.00001$; table 1). The percentage of cases with one or more SSFs did not change during these years, but the percentage of cases without or with an unlikely relation of SSFs to death increased $(p=0.028)$. Antepartum high risk selection increased from $70 \%$ to $84 \%$ during the years $(\mathrm{p}=0.0001)$.

\section{Strengths and limitations}

Audits by a multidisciplinary team of healthcare professionals themselves (internal audit), is a feasible way to increase implementation of the audit results/recommendations in local practice. In the chosen approach in the Netherlands an independent chairperson has proven instrumental to optimise audit performance. ${ }^{18}$

This study concerns term perinatal deaths of recent date, the last cases of 2012 were audited in June 2013. Most audits are performed within 3-6 months after death, which minimises the potential loss of knowledge/ memory and details of the cases and circumstances that contributed to them.

Not all term cases of perinatal death are audited. Characteristics of the audited cases, however, are comparable with all term perinatal deaths in the national registration of the PRN; the registered cases were also comparable except for fewer cases with non-Caucasian ethnicity and fewer cases with birth weight $<2000 \mathrm{~g}$. This suggests that cases have not been avoided systematically or were lost for discussion in the audit.

Of all audited cases information was insufficient in $11 \%$ for SSF assessment. This percentage remained similar during the years and is a point of concern for the years ahead.

It is unknown whether all audit meetings take place in the most optimal and consistent way.

However, in our study the percentage of cases with assessed SSFs remained about the same during the years. In our view this fits with a stable audit method.

Knowledge of the outcome can influence the judgement of the care and the relation between the SSFs and the outcome, especially when the outcome is perinatal death. ${ }^{29}{ }^{30}$ Although participants may have assessed more or less harshly, the overall nationwide collected output of cases with SSF was quite consistent.

The cause of death according to the Tulip classification was classified as unknown in $32 \%$ of the cases in our study. This high percentage suggests that improvement may be feasible by further training of the audit teams in using the Tulip classification in addition to the desirability of more autopsies and placenta biopsies. ${ }^{25} 31$

\section{Comparison with other studies}

There are no other studies with national internal perinatal audit programmes, so we can only compare with earlier regional (external) audit studies.

\section{SSF}

In $36 \%$ of the audited cases in our study the audit group did not identify or assess any SSF. This is lower 


\begin{tabular}{|c|c|c|c|c|c|}
\hline \multirow[b]{2}{*}{ Characteristics } & \multicolumn{4}{|c|}{ Table 7 Characteristics of term perinatal deaths in PARS and PRN-Audit versus PRN 2010-2012 } & \multirow[b]{2}{*}{ p Value* } \\
\hline & $n$ & Per cent & $\mathbf{n}$ & Per cent & \\
\hline Gestational age (weeks) & & & & & 0.91 \\
\hline $37.0-40.6$ & 598 & 85 & 930 & 84 & \\
\hline$\geq 41.0$ & 109 & 15 & 172 & 16 & \\
\hline Congenital malformations & 135 & 19 & 238 & 22 & 0.20 \\
\hline Moment of death & & & & & 0.40 \\
\hline Fetal & 440 & 62 & 718 & 65 & \\
\hline Neonatal & 259 & 37 & 384 & 35 & \\
\hline Unknown period & 8 & 1 & & & \\
\hline \multirow[b]{3}{*}{ Characteristics } & 707 & 100 & 1102 & 100 & \\
\hline & \multicolumn{2}{|c|}{ PRN-Audit } & \multicolumn{2}{|l|}{ PRN } & \\
\hline & $\mathrm{n}$ & Per cent & $\mathrm{n}$ & Per cent & p Value* \\
\hline \multicolumn{6}{|l|}{ Age mother (years) } \\
\hline$<20$ & 6 & 1 & 11 & 1 & 0.37 \\
\hline$\geq 35$ & 243 & 26 & 292 & 26 & 0.71 \\
\hline Non-Caucasian ethnicity & 185 & 20 & 257 & 23 & 0.04 \\
\hline Congenital malformation & 194 & 21 & 238 & 22 & 0.57 \\
\hline Period of death & & & & & 0.94 \\
\hline Fetal & 613 & 65 & 718 & 65 & \\
\hline Neonatal & 330 & 35 & 384 & 35 & \\
\hline \multicolumn{6}{|l|}{ Birth weight (grams) } \\
\hline$<2000$ & 30 & 3 & 60 & 5 & 0.01 \\
\hline 2000-2499 & 85 & 9 & 98 & 9 & 0.92 \\
\hline$\geq 4500$ & 22 & 2 & 22 & 2 & 0.60 \\
\hline \multicolumn{6}{|l|}{ Gestational age (weeks) } \\
\hline $37.0-39.6$ & 579 & 61 & 707 & 64 & 0.20 \\
\hline $40.0-41.6$ & 341 & 36 & 371 & 34 & 0.12 \\
\hline$\geq 42.0$ & 23 & 2 & 24 & 2 & 0.69 \\
\hline Total & 943 & & 1102 & & \\
\hline
\end{tabular}


than in earlier regional studies in the Netherlands in 1996-1997 and 2003-2004 with 40-45\%. ${ }^{12}{ }^{15}$ A possible explanation is that professionals are more critical about their own delivered care than external audit panels are. Otherwise these studies were performed 10 or even more years ago and in the meantime many guidelines have been developed and could be used as references for SSF.

In $11 \%$ of all cases insufficient information was present for SSF assessment. In earlier audit studies in the Netherlands this percentage was 2-4. ${ }^{12}{ }^{15}$ However, these audits (and narratives) were prepared by one or two dedicated researchers while in the nationwide audit each PCG has to gather all information for the narrative during their daily work.

\section{SSF and relation to death}

The audit groups found a probable or very probable relation of SSFs to death in $8 \%(n=57)$ of all discussed term perinatal deaths. In the LPAS study, a regional external audit in 2003-2004 in the Netherlands, this was $9 \% .^{15}$ In earlier studies (external audits), only the combined outcome of possible and probable relation of SSF and death is given. In $25-30 \%$ a combined possible or probable relation is found in the Netherlands and even $46 \%$ in 10 European regions in 1993-1998 (Euronatal study). ${ }^{1} \quad 11 \quad 12 \quad 30$ These combined percentages were higher than in our recent study $(21 \%)$ and in the earlier LPAS study (19\%). ${ }^{15}$ It is possible that these differences can be (partly) explained by quality of care improvement during the past 20 years. Otherwise it would be desirable to examine whether, compared with external review, our method of internal review with an external chair was more or less likely to identify SSFs with possible/probable relation to death.

\section{Classification of perinatal death}

At $36 \%$, a placental cause of death in the Tulip classification was the most frequent. This is similar to the results of the LPAS study. ${ }^{15}$ Comparison of the prevalence of perinatal death causes with other studies is difficult since those reports do not show the term period with enough separation for proper comparison. In a university clinic with preterm births included, $27 \%$ placental cause of death was found. ${ }^{25}$

\section{Implications of the study and further research}

A systematic method of perinatal audit has been implemented by all PCGs in The Netherlands. Audits generated many recommendations for quality of care improvements, which are in progress towards implementation. The infrastructure of the perinatal audit in the Netherlands had been secured and more topics can be chosen in the future for audit in perinatal care. For the years 2013-2015 the focus is on term intrapartum and neonatal death and admission to an NICU for neonatal asphyxia.
Further evaluation of time trends on term perinatal mortality will be an important focus for the years 20132015. The evaluation so far is based on only 3 years, which is rather short to draw conclusions about trends in an outcome as rare as perinatal mortality.

It is assumed that the chance of uptake of actions formulated by local professionals themselves is greater than the uptake of top down imposed advice. In general, the implementation of changes in care proves to be difficult. $^{32}$ At a national level the professional organisations involved now cooperate in college perinatal care $(\mathrm{CPZ})$, instituted by the Ministry of Health (http://www. collegepz.nl/organisatie). CPZ is coordinating desirable changes in perinatal care.

During the 3 years studied, term perinatal mortality decreased. The percentage of cases with SSF without a relation to death increased while the percentage of cases with SSF and a probable relation to death decreased. Although a direct relationship cannot be proven, the parallel is striking with the synchrony of audit implementation and subsequently declining perinatal mortality in Norway. ${ }^{9}$

Antepartum high-risk selection increased during the years 2010-2012. This can suggest that risk selection became more accurate but this needs further investigation. ${ }^{33}$ Some recommendations from the audits have already been implemented, such as the need for developing a new national guideline for 'reduced fetal movements'. ${ }^{34}$

\section{Conclusion}

Within a short time period a systematic method of internal perinatal audit has been implemented by all PCGs in the Netherlands. Audits performed by healthcare professionals themselves generated many recommendations for quality of care improvements, which are in progress towards implementation. It is possible that the audit contributed to the decrease in term perinatal mortality. With ongoing audits quality of perinatal care can be continuously monitored and instruments for quality of care improvement developed.

These findings can be a stimulus for introduction of nationwide internal perinatal audit in other countries and in other medical disciplines.

Author affiliations

${ }^{1}$ Foundation Perinatal Audit in The Netherlands (PAN), Utrecht, The Netherlands

${ }^{2}$ Department of Medical Informatics, Academic Medical Center, Amsterdam, The Netherlands

${ }^{3}$ Department of Obstetrics and Gynaecology, University of Groningen, Groningen, The Netherlands

${ }^{4}$ Department of Neonatology, University Medical Center, Utrecht,

The Netherlands

${ }^{5}$ National Institute for Public Health and the Environment (RIVM), Bilthoven, The Netherlands

Acknowledgements This study would not have been possible without the very committed Dutch perinatal professionals: midwives, obstetricians, pediatricians/neonatologists, nurses, pathologists and others who participated 
in the audits. The Netherlands Perinatal Registry provided the data of term perinatal mortality. The perinatal audit as programme is funded by The Ministry of Health (VWS).

Contributors ME, AW, JJE, HB, AR, PA, HM and HB had the core idea for this study. AR and ME prepared and analysed the data and/or interpreted the results. AW, ME and AR wrote the draft of the article. JJE, HB, PA, HM and $\mathrm{HB}$ commented on the manuscript and approved the final version.

Funding This research received no specific grant from any funding agency in the public, commercial or not-for-profit sectors.

Competing interests None.

Ethics approval The national Perinatal Registry of The Netherlands (PRN) provided data from the PRN and PRN-Audit, registered as data request 11.38 , 13.45, 13.51, 13.61, 14.09 (http://www.perinatreg.nl). The PRN has given permission for the analysis of their data.

Provenance and peer review Not commissioned; externally peer reviewed.

Data sharing statement Data set can be requested for at the board of Foundation Perinatal Audit in The Netherlands (PAN) info@perinataleaudit.nl.

Open Access This is an Open Access article distributed in accordance with the Creative Commons Attribution Non Commercial (CC BY-NC 4.0) license, which permits others to distribute, remix, adapt, build upon this work noncommercially, and license their derivative works on different terms, provided the original work is properly cited and the use is non-commercial. See: http:// creativecommons.org/licenses/by-nc/4.0/

\section{REFERENCES}

1. Richardus JH, Graafmans WC, Verloove-Vanhorick SP, et al. Differences in perinatal mortality and suboptimal care between 10 European regions: results of an international audit. BJOG 2003:110:97-105.

2. Achterberg PW, Kramers PGN. Een gezonde start? Sterfte rond de geboorte in Nederland: trends en oorzaken vanuit een internationaal perspectief. RIVM-rapport nr. 271558003 (in Dutch). Bilthoven: National Institute for Public Health and the Environment (RIVM), 2001. http://www.rivm.nl/bibliotheek/rapporten/271558003.pdf

3. Buitendijk SE, Nijhuis JG. [High perinatal mortality in the Netherlands compared to the rest of Europe]. Ned Tijdschr Geneeskd 2004;148:1855-60.

4. Ravelli AC, Tromp M, van Huis M, et al. Decreasing perinatal mortality in the Netherlands, 2000-2006: a record linkage study. J Epidemiol Community Health 2009;63:761-5.

5. Mohangoo AD, Buitendijk SE, Hukkelhoven CW, et al. [Higher perinatal mortality in the Netherlands than in other European countries: the Peristat-II study]. Ned Tijdschr Geneeskd 2008;152:2718-27.

6. Dunn PM, Mcllwaine G. Perinatal audit. A report produced for the European Association of Perinatal Medicine. New York, 1996.

7. Dahl LB, Berge LN, Dramsdahl H, et al. Antenatal, neonatal and post neonatal deaths evaluated by medical audit. A populationbased study in northern Norway-1976 to 1997. Acta Obstet Gynecol Scand 2000;79:1075-82.

8. Stray-Pedersen B. Perinatal mortality in Norway: experience with perinatal audit. Eur J Obstet Gynecol Reprod Biol 1991;41:20-2.

9. Bergsjo P, Bakketeig LS, Langhoff-Roos J. The development of perinatal audit: 20 years' experience. Acta Obstet Gynecol Scand 2003:82:780-8.

10. Eskes M, van Alten D, Treffers PE. The Wormerveer study; perinata mortality and non-optimal management in a practice of independent midwives. Eur J Obstet Gynecol Reprod Biol 1993;51:91-5.

11. de Reu PAOM, Nijhuis JG, Oosterbaan HP, et al. Perinatal audit on avoidable mortality in a Dutch rural region: a retrospective study. Eur J Obstet Gynecol Reprod Biol 2000;88:65-9.
12. Vredevoogd CB, Wolleswinkel-vdBosch JH, Amelink-Verburg MP, et al. [Perinatal mortality assessed: results of a regional audit]. Ned Tijdschr Geneeskd 2001;145:482-7.

13. van Diem MT, de Reu PAOM, Eskes M, et al. National perinatal audit, a feasible initiative for the Netherlands!? A validation study. Acta Obstet Gynecol Scand 2010;89:1168-73.

14. CVZ. Verloskundig Vademecum. Diemen: College voor zorgverzekeringen, 2003. http://www.knov.nl/uploads/knov.nl/knov_ downloads/769/file/Verloskundig\%20Vademecum\%202003.pdf

15. CVZ. Landelijke Perinatal Audit Studie (LPAS). Diemen: College voor zorgverzekeringen, 2005. http://www.perinataleaudit.nl/inc/ getdocument.cfm?filename=upload/LPAS\%20(2005).pdf

16. Leeman LD, Waelput AJM, Eskes M, et al. Op weg naar de landelijke invoering van perinatale audit. RIVM-rapport 270032005 (in Dutch). Bilthoven: National Institute for Public Health and the Environment (RIVM), 2007. http://www.rivm.nl/bibliotheek/rapporten/ 270032005.pdf

17. de Reu PAOM, van Diem MT, Eskes M, et al. The Dutch Perinatal Audit Project: a feasibility study for nationwide perinatal audit in the Netherlands. Acta Obstet Gynecol Scand 2009;88:1201-8.

18. van Diem MT, Timmer A, Bergman KA, et al. The implementation of unit-based perinatal mortality audit in perinatal cooperation units in the northern region of the Netherlands. BMC Health Serv Res 2012;12:195.

19. van Alten D, Eskes M, Treffers PE. Midwifery in the Netherlands The Wormerveer study; selection, mode of delivery, perinatal mortality and infant morbidity. Br J Obstet Gynaecol 1989;96:656-62.

20. Amelink-Verburg MP, Verloove-Vanhorick SP, Hakkenberg RM, et al. Evaluation of 280,000 cases in Dutch midwifery practices: a descriptive study. BJOG 2008;115:570-8.

21. Bleker OP, Hulst LAMvd, Eskes M, et al. Place of birth: evidence for best practice. In: Bonnar J, Dunlop W, eds. Recent advances in obstetrics and gynaecology. London: Royal Society of Medicine Press, 2005:77-100.

22. Hey EN, Lloyd DJ, Wigglesworth JS. Classifying perinatal death: fetal and neonatal factors. Br J Obstet Gynaecol 1986;93:1213-23.

23. Chan A, King JF, Flenady V, et al. Classification of perinatal deaths: development of the Australian and New Zealand classifications. J Paediatr Child Health 2004;40:340-7.

24. Gardosi J, Kady SM, McGeown P, et al. Classification of stillbirth by relevant condition at death $(\mathrm{ReCoDe})$ : population based cohort study. BMJ 2005;331:1113-17

25. Korteweg FJ, Gordijn SJ, Timmer A, et al. The Tulip classification of perinatal mortality: introduction and multidisciplinary inter-rater agreement. BJOG 2006;113:393-401.

26. PAN. A terme sterfte 2010-2012: Perinatale audit op koers (in Dutch). Utrecht: Stichting Perinatale Audit Nederland, 2014. http:// www.perinataleaudit.nl/inc/getdocument.cfm?filename=upload/docs/ Jaarrapport PAN 2010-2012.pdf

27. WHO. International statistical classification of diseases and related health problems. Vol 2. Geneva: World Health Organization, 1993.

28. Vincent $\mathrm{C}$. Understanding and responding to adverse events. $N E n g$ J Med 2003;348:1051-6.

29. Andersen KV, Hermann N, Gjorup T. Perinatal audit. Are experts biased by knowledge of outcome? A controlled study. Dan Med Bull 1992;39:197-9.

30. Amelink-Verburg MP, van Roosmalen J, Roelofsen JM, et al. [Evaluation and validation of a perinatal death audit by means of feedback to the caregivers]. Ned Tijdschr Geneeskd 2003;147:2333-7.

31. Gordijn SJ, Erwich JJ, Khong TY. The perinatal autopsy: pertinent issues in multicultural Western Europe. Eur J Obstet Gynecol Reprod Biol 2007;132:3-7.

32. Grol R, Wensing M. Implementation of quality assurance and medical audit: general practitioners' perceived obstacles and requirements. Br J Gen Pract 1995;45:548-52.

33. Ravelli AC, Jager KJ, de Groot $\mathrm{MH}$, et al. Travel time from home to hospital and adverse perinatal outcomes in women at term in the Netherlands. BJOG 2011;118:457-65.

34. NVOG, KNOV. Richtlijn 'Verminderde kindsbewegingen tijdens de zwangerschap'. Utrecht: KNOV, NVOG, 2014. 